\title{
QUALIDADE DA ÁGUA COMO REFLEXO DE ATIVIDADES ANTRÓPICAS EM BACIAS HIDROGRÁFICAS DO NORDESTE, BRASIL
}

Adriana Maria Cunha da Silva ${ }^{1}$ Maristela Casé ${ }^{2}$

Denise Vieira Lopes ${ }^{3}$

Resumo: A sustentabilidade hídrica constitue em fator primordial para o desenvolvimento dos grupos humanos. Este trabalho teve como objetivo avaliar os Índices de Qualidade da Água (IQA), Estado Trófico (IET), Balneabilidade (IB) e o da Comunidade Fitoplanctônica (ICF), das bacias hidrográficas dos rios São Francisco, Paraíba, Pajeú e Moxotó. As informações foram disponibilizadas pelo Ministério da Integração Nacional Brasileiro referente a coletas no período de 2013/2014. pH, turbidez, oxigênio dissolvido, coliformes termotolerantes, DBO, fósforo total e clorofila-a apresentaram resultados fora dos limites estabelecidos pela Resolução CONAMA no 357/2005 para águas classe II. Os resultados evidenciam a influência antrópica na qualidade da água dos rios e reservatórios avaliados, e servem como subsídio para o desenvolvimento de pesquisas na gestão dos ecossistemas hídricos do semiárido brasileiro.

Palavras-chave: Uso do solo. Índices de qualidade da água. Semiárido. Rio. Reservatório.

\section{WATER QUALITY AS A REFLEX FOR ANTHROPIC ACTIVITIES IN WATERSHEDS MANAGEMENT AT NORTHEAST, BRAZIL}

Abstract: Water sustainability establishes a key factor for human group development. This study aimed to verify the anthropic activities influence through the Water Quality Index (WQI), Trophic State Index (TSI), Recreational Water Quality Index (RWQI) and Phytoplankton Community Index (PCI) for water quality at São Francisco, Paraíba, Pajeú and Moxotó river basins stretches. Information were provided by Brazilian National Integration Ministry concerning to biannual samplings during 2013/2014. $\mathrm{pH}$, turbidity, dissolved oxygen, fecal coliform, COD, total phosphorus and chlorophyll-a variables showed results outside the limits established by CONAMA Resolution 357/2005 for class II waters. These results showed a human influence on the water quality of rivers and reservoirs assessed, and they will be served as a support for future research development for water ecosystems management at Brazilian semiarid region.

Keywords: Soil management. Water quality index. Semiarid. River. Reservoir.

\section{CALIDAD DEL AGUA COMO REFLEJO DE ACTIVIDADES ANTRÓPICAS EN CUENCAS HIDROGRÁFICAS DEL NORDESTE, BRASIL}

Resumen: La sostenibilidad del agua establece un factor clave para el desarrollo del grupo humano. Este estudio tuvo como objetivo verificar la influencia de las

\footnotetext{
${ }^{1}$ Universidade do Estado da Bahia, Campus VIII, Departamento de Educação, Paulo Afonso, Brasil, adricunha@hotmail.com, https://orcid.org/0000-0002-6549-684X

2 Universidade do Estado da Bahia, Campus VIII, Departamento de Educação, Paulo Afonso, Brasil, maristelacase@gmail.br, https://orcid.org/0000-0001-9935-7912

${ }^{3}$ Universidade do Estado da Bahia, Campus VIII, Departamento de Educação, Paulo Afonso, Brasil, denise_vieira@msn.com, https://orcid.org/0000-0001-6900-6708
} 
actividades antrópicas a través del índice de calidad del agua (WQI), índice de estado trófico (TSI), índice de calidad de agua recreativa (RWQI) e índice de comunidad de fitoplancton ( $\mathrm{PCl}$ ) para la calidad del agua en São Francisco, Paraíba, Pajeú y Las cuencas de los ríos Moxotó se extienden. La información fue proporcionada por el Ministerio de Integración Nacional de Brasil con respecto a los muestreos bianuales durante 2013/2014. pH, turbidez, oxígeno disuelto, coliformes fecales, DQO, fósforo total y clorofila a mostraron resultados fuera de los límites establecidos por la Resolución CONAMA 357/2005 para aguas de clase II. Estos resultados mostraron una influencia humana en la calidad del agua de ríos y embalses evaluados, y se servirán como un apoyo para el desarrollo de investigación futura para el manejo de los ecosistemas acuáticos en la región semiárida brasileña.

Palabras clave: Manejo del suelo. Índice de calidad del agua. Semiárido. Río. Depósito.

\section{Introdução}

Dentre os desafios atuais na esfera dos problemas socioambientais, destacase a busca pela sustentabilidade hídrica. Essa preocupação ocorre devido ao valor social, econômico e cultural dos recursos hídricos, assim como, em função dos altos níveis de interferência antrópica na sua disponibilidade qualitativa e o registro de conflitos associados (FRACALANZA, 2005; REIS e PEREIRA FILHO, 2006; COELHO et al., 2009; CARVALHO e MELO,2012; RIBEIRO 2014; SOUZA et al., 2014).

Nessa perspectiva, os estudos que permitam avaliar as condições dos ambientes aquáticos são imprescindíveis, já que auxiliam em tomadas de decisão, e possibilitam a conservação e proteção dos recursos hídricos, assegurando dessa forma o desenvolvimento dos grupos humanos. Especialmente regiões onde apresenta pouca disponibilidade hídrica, como o semiárido do Nordeste (PALÁCIO et al., 2009; SILVA, AZEVEDO e ALVES, 2014).

A problemática da sustentabilidade hídrica também assume particular relevância em corpos hídricos destinados ao abastecimento púbico, incluindo nesta análise aqueles inseridos no projeto de Integração do rio São Francisco com bacias hidrográficas do Nordeste Setentrional (PISF). De acordo com Ministério da Integração Nacional (2014) o PISF visa ofertar água para mais de 12 milhões de pessoas de 390 municípios do Nordeste Setentrional, e, portanto, é necessário que a qualidade da água desses mananciais não esteja comprometida.

Os índices de qualidade da água constituem em importante ferramenta de monitoramento dos corpos hídricos, por permitirem de forma rápida e sintética a 
caracterização da qualidade da água, convertendo num único número de fácil compreensão, não só no meio científico como entre o público geral, diversos parâmetros físicos, químicos e biológicos (TOLEDO e NICOLELLA, 2002; ALMEIDA e SCHRWARZBOLD, 2003; CARVALHO et al., 2011; NUNES, SILVA e MATOS, 2011).

A Companhia Ambiental do Estado de São Paulo (CETESB) dispõe de uma série de índices para monitorar a qualidade de corpos hídricos. Entre eles, merecem destaque: O Índice de Qualidade da Água (IQA), que indica o lançamento de efluentes sanitários para o corpo d'água; O Índice do Estado Trófico (IET), utilizado para avaliar o nível de concentração de fósforo e clorofila-a na água e seu efeito relacionado ao crescimento excessivo das algas, classificando os corpos d'água em diferentes graus de trofia; $O$ Índice de Comunidade Fitoplanctônica (ICF), que tem a finalidade de separar em categorias a qualidade da água de acordo com a dominância dos grandes grupos que compõem o fitoplâncton, a densidade dos organismos e o IET; e O Índice de Balneabilidade (IB) que visa avaliar a qualidade da água para fins de recreação de contato primário, visto que a determinação da concentração dos coliformes assume importância como parâmetro indicador da possibilidade da existência de microorganismos patogênicos, responsáveis pela transmissão de doenças de veiculação hídrica, tais como febre tifóide, febre paratifóide, disenteria bacilar e cólera (ARAUJO, SANTOS e ARAUJO, 2007; CETESB, 2012).

Face ao exposto, 0 presente trabalho teve como objetivo avaliar por intermédio do IQA, IET, IB, ICF e seus respectivos parâmetros, a qualidade da água de rios e reservatórios localizados no semiárido brasileiro, inseridos no PISF, e que apresentam diferentes usos e ocupação do solo no seu entorno.

\section{Metodologia}

A pesquisa foi realizada em 15 estações, distribuídas nas bacias hidrográficas dos rios São Francisco, Paraíba, Pajeú e Moxotó, que compreendem o eixo leste do PISF (Tabela 01).

Para a identificação das atividades antrópicas foi realizada uso de imagens de satélite disponibilizadas no Google Earth, referente ao entorno de cada ponto amostral, utilizando as respectivas coordenadas UTM, e visitas in loco no período de agosto a setembro de 2014. 
Os dados referentes às coletas e análises dos parâmetros físicos, químicos e biológicos correspondem a dados secundários disponibilizados pelo Ministério da Integração Nacional Brasileiro. As amostras de água foram coletadas em quatro campanhas, com frequência semestral, durante os anos de 2013 (1 $1^{\underline{a}}$ e $2^{\underline{a}}$ Campanha) e 2014 (3ª e 4⿳亠丷a Campanha).

Tabela 01. Identificação e coordenadas (UTM) das estações amostrais nas bacias hidrográficas dos rios São Francisco, Paraíba, Pajeú e Moxotó.

\begin{tabular}{|c|c|c|c|}
\hline & Bacia/ Estação Amostral & Longitude & Latitude \\
\hline \multicolumn{4}{|c|}{ SÃO FRANCISCO } \\
\hline PA 1 & Reservatório Itaparica - Captação Eixo Leste & -38.404214 & -8.822060 \\
\hline PA 2 & Lago de Itaparica - Orla de Nova Petrolândia & -38.299721 & -9.020081 \\
\hline \multicolumn{4}{|c|}{ PARAÍBA (PB) } \\
\hline PA 3 & Açude Poções (Eixo da Barragem) & -36.997378 & -7.889249 \\
\hline PA 4 & $\begin{array}{l}\text { Rio Paraíba - Montante do Remanso do Açude } \\
\text { Camalaú }\end{array}$ & -36.886644 & -7.870969 \\
\hline PA 5 & Açude Camalaú - Eixo da Barragem & -36.833082 & -7.887183 \\
\hline PA 6 & Rio Paraíba - Caraúbas & -36.499784 & -7.717647 \\
\hline PA 7 & Açude Boqueirão - Eixo da Barragem & -36.140049 & -7.487228 \\
\hline PA 8 & Jusante do Açude Boqueirão & -36.065628 & -7.505249 \\
\hline PA 9 & Bodocongó & -41.999413 & -7.527963 \\
\hline PA 10 & Rio Paraíba - Jusante do Açude Acauã & -41.172146 & -7.185091 \\
\hline \multicolumn{4}{|c|}{ PAJEÚ (PE) } \\
\hline PA 11 & $\begin{array}{c}\text { Riacho do Navio, afluente do Açude Barra do } \\
\text { Juá }\end{array}$ & -38.031513 & -8.277248 \\
\hline PA 12 & Açude Barra do Juá - Eixo da Barragem & -38.073888 & -8.446096 \\
\hline PA 13 & $\begin{array}{l}\text { Rio Pajeú - após a confluência com o riacho } \\
\text { do Navio }\end{array}$ & -38.579882 & -8.639463 \\
\hline \multicolumn{4}{|c|}{ MOXOTÓ (PE) } \\
\hline PA 14 & Açude Poço da Cruz - Eixo da Barragem & -37.706812 & -8.507689 \\
\hline PA 15 & Rio Moxotó - Jusante do Açude Poço da Cruz & -37.705651 & -8.509891 \\
\hline
\end{tabular}

Fonte: Adaptado pela autora a partir do Plano Básico Ambiental- PBA-22 do PISF (2011).

Amostras superficiais de água nas estações de rio e reservatório foram coletadas utilizando recipiente de polietileno. Garrafa de Van Dorn foi utilizada para coletas de água em profundidade nos reservatórios. 
Com sonda multiparamétrica (HORIBA, modelo U-50 Series) os parâmetros de campo, como temperatura $\left({ }^{\circ} \mathrm{C}\right)$, turbidez (UNT), oxigênio dissolvido $\left(\mathrm{mg}^{-\mathrm{L}^{-1}}\right)$ e $\mathrm{pH}$ foram obtidos in loco. Os demais parâmetros: nitrogênio total (mg.L-1), DBO (mg. $\left.\mathrm{L}^{-1}\right)$, coliformes termotolerantes $(\mathrm{NMP} / 100 \mathrm{~mL})$, resíduos totais $\left(\mathrm{mg}^{-\mathrm{L}^{-1}}\right)$, fósforo total (mg. $\left.\mathrm{L}^{-1}\right)$ e clorofila-a $\left(\mu \mathrm{g} . \mathrm{L}^{-1}\right)$ foram analisados no laboratório Agrosafety, de acordo com Standard Methods for the Examination of Water and Wastewater (APHA, 2005).

Os índices utilizados foram calculados de acordo com CETESB (2012). No Índice de Qualidade da Água (IQA) foi calculado o produto ponderado da qualidade da água correspondente as variáveis que compõem o índice (coliformes termotolerantes, $\mathrm{pH}, \mathrm{DBO}$, nitrogênio, fósforo total, temperatura, turbidez, resíduo total e OD), de acordo com a equação 1 .

$$
\text { (1) IQA }=\prod_{i=1}^{n} q i w^{i}
$$

Onde:

IQA: Índice de Qualidade das Águas, um número entre 0 e 100;

qi: qualidade do i-ésimo parâmetro, um número entre 0 e 100, obtido da respectiva "curva média de variação de qualidade", em função de sua concentração ou medida.

wi: peso correspondente ao i-ésimo parâmetro, um número entre 0 e 1 , atribuído em função da sua importância para a conformação global de qualidade.

n: número de variáveis que entram no cálculo do IQA.

Após o cálculo do IQA, a qualidade da água foi classificada como Ótima (79 $\leq \mid Q A \leq 100)$, Boa (51 $\leq \mid Q A \leq 79)$, Regular (36 $\leq \mid Q A \leq 51)$, Ruim $(19 \leq \mid Q A \leq 36)$ ou Péssima (QA $\leq 19)$.

Para o Índice do Estado Trófico (IET), utilizou- se a concentração de fósforo total e clorofila-a, e o IET final ou IET médio foi resultante da média aritmética simples relativa ao IET (PT) e o IET (CL), aplicados conforme as equações 2, 3 e 4:

Rios (2)

IET $(C L)=10 x(6-((-0,7-0,6 \times(\ln C L)) / \ln 2))-20$

IET $(\mathrm{PT})=10 \mathrm{x}(6-((0,42-0,36 \mathrm{x}(\operatorname{In} \mathrm{PT})) / \ln 2))-20$

Reservatórios (3)

$\operatorname{IET}(C L)=10 x(6-((0,92-0,34 \times(\ln C L)) / \ln 2))$

IET $(P T)=10 \times(6-(1,77-0,42 \times(\ln P T) / \ln 2))$

IET médio (4) 
$\mathrm{IET}=[\mathrm{IET}(\mathrm{PT})+\mathrm{IET}(\mathrm{CL})] / 2$

Onde:

PT: concentração de fósforo total medida à superfície da água, em mg.L-1;

$\mathrm{CL}$ : concentração de clorofila a medida à superfície da água, em $\mu \mathrm{g} \cdot \mathrm{L}-1$;

In: logaritmo natural.

Com a obtenção do IET médio, os rios e reservatórios foram enquadrados em diferentes classes de trofia: Ultraoligotrófico (IET $\leq 47)$, Oligotrófico $(47<\mathrm{IET} \leq 52)$, Mesotrófico $(52<\mathrm{IET} \leq 59)$, Eutrófico $(59<\mathrm{IET} \leq 63)$, Supereutrófico $(63<\mathrm{IET} \leq 67)$ e Hipereutrófico (IET> 67).

Através da dominância dos grandes grupos que compõem o fitoplâncton, a densidade dos organismos e o IET, foi aplicado o Índice da Comunidade Fitoplanctônica (ICF). A classificação da qualidade da água baseou-se na média aritmética das três ponderações parciais relativas à dominância, densidade e valor de IET, conforme Tabela 02.

Enquanto o índice de Balneabilidade (IB) foi aplicado por meio da análise da concentração de coliforme termotolerante (NMP.100 $\mathrm{mL}^{-1}$ ) nas amostras de água coletadas nos rios e reservatórios em estudo, e sua classificação determinada através de uma síntese dos resultados por campanha (Tabela 03).

Para os cálculos dos índices e confecção das tabelas utilizou-se a média simples dos parâmetros na superfície e no fundo para os pontos de reservatórios. Cada parâmetro que compõem os índices utilizados na presente pesquisa foi comparado com os limites exigidos pela resolução do CONAMA no 357 de 17 de março de 2005.

Além disso, os resultados dos parâmetros analisados nas estações amostrais também foram submetidos à análise estatística multivariada (Análise de Componentes Principais- ACP) no software PAST 3.0 (HAMMER et al., 2001), a fim de identificar os parâmetros mais significativos na determinação da qualidade da água nos corpos hídricos em análise.

Tabela 02. Classificação da qualidade da água em relação ao Índice de Comunidade Fitoplanctônica- ICF.

\begin{tabular}{ccc}
\hline Categoria & Ponderação & Níveis \\
\hline ÓTIMA & 1 & $\begin{array}{c}\text { Não há dominância entre os grupos } \\
\text { Densidade total }<1.000 \text { org. } \mathrm{mL}^{-1}\end{array}$ \\
\hline
\end{tabular}




\section{$\mathrm{IET} \leq 52$}

Dominância de Clorofíceas (Desmidiáceas) ou

BOA

2

\section{Diatomáceas}

Densidade total $>1.000 \mathrm{e}<5.000$ org. $\mathrm{mL}^{-1}$

$$
52<\text { IET } \leq 59
$$

Dominância de Clorofíceas (Chlorococcales),

REGULAR

3

Fitoflagelados ou Dinoflagelados

Densidade total $>5.000$ e $<10.000$ org. $\mathrm{mL}^{-1}$

$$
59<\mathrm{IET} \leq 63
$$

Dominância de Cianobactérias ou Euglenofíceas 
Tabela 03. Classificação da qualidade da água em relação ao Índice de Balneabilidade - IB.

\begin{tabular}{ccc}
\hline \multicolumn{2}{c}{ Categoria } & Coliforme Termotolerante (UFC.100 mL $^{-1}$ ) \\
\hline ÓtIMA & $\begin{array}{c}\text { Classificada como } \\
\text { EXCELENTE }\end{array}$ & Máximo de 250 em $75 \%$ ou mais das \\
BOA & $\begin{array}{c}\text { Classificada como } \\
\text { PRÓPRIA }\end{array}$ & Entre 251 e 1000 em $75 \%$ ou mais das \\
REGULAR & $\begin{array}{c}\text { Classificada como } \\
\text { IMPRÓPRIA }\end{array}$ & Superior a 1000 em até $25 \%$ das amostras \\
& Classificada como & Superior a 1000 entre $25 \%$ e $50 \%$ das \\
RUIM & IMPRÓPRIA & amostras \\
& Classificada como & Superior a 1000 em mais de $50 \%$ das \\
& IMPRÓPRIA & amostras
\end{tabular}

Fonte: adaptado pela autora a partir de CETESB (2012), Carvalho et al. (2009).

\section{Resultados e Discussão}

\section{Variáveis limnológicas e os índices avaliados}

A Tabela 04 apresenta os resultados dos parâmetros (temperatura, nitrogênio total e resíduos totais) utilizados no IQA e que não possuem limite preconizado pela Resolução CONAMA 357/05 para águas classe II.

Os valores de temperatura variaram entre $21,8^{\circ} \mathrm{C}$ e $29,8^{\circ} \mathrm{C}$. Trabalhos desenvolvidos por outros autores (DONADIO, GALBIATTI e PAULA, 2005; BARROS, SOUZA e SOUZA, 2011; CABRAL et al., 2015) apontaram aumento térmico das águas associado a supressão da cobertura vegetal, já que essas impedem a incidência de forma direta da radiação solar sobre o corpo hídrico. 
Tabela 04. Valores de Temperatura $\left({ }^{\circ} \mathrm{C}\right)$, Nitrogênio Total (mg. $\left.\mathrm{L}^{-1}\right)$ e Resíduo Total (mg. $\mathrm{L}^{-1}$ ) registrados nas estações amostrais das bacias dos rios São Francisco, Paraíba, Pajeú e Moxotó no período de 2013 a 2014. Dados ausentes (-). Campanhas (1ª , 2ª , $3^{\mathbf{a}}$ e 4).

\begin{tabular}{|c|c|c|c|c|c|c|c|c|c|c|c|c|c|c|c|c|}
\hline \multirow[t]{2}{*}{ PARÂMETROS } & \multicolumn{3}{|c|}{$\begin{array}{c}\text { SÃO } \\
\text { FRANCISCO }\end{array}$} & \multicolumn{8}{|c|}{ PARAÍBA } & \multicolumn{3}{|c|}{ PAJEÚ } & \multicolumn{2}{|c|}{ мохото́ } \\
\hline & & P1 & P2 & P3 & P4 & P5 & P6 & P7 & P8 & P9 & P10 & P11 & P12 & P13 & P14 & P15 \\
\hline & $1^{a}$ & - & - & - & - & - & - & - & - & - & - & - & - & - & - & - \\
\hline Temperatura & $2^{\mathbf{a}}$ & 25,2 & 24,8 & 23,4 & - & 24,6 & - & 23,7 & 25,4 & - & 24,5 & - & 26,6 & 26,4 & 23,7 & 22,7 \\
\hline \multirow[t]{2}{*}{$\left({ }^{\circ} \mathrm{C}\right)$} & $3^{\mathbf{a}}$ & 26,8 & 26,1 & 25,3 & 26,3 & 26,1 & 26,3 & 24,8 & 26,9 & 26,5 & 25,4 & 24,3 & 25,9 & 29,8 & 25,3 & 24,3 \\
\hline & $4^{a}$ & 25,0 & 25,9 & 21,8 & - & 23,9 & - & 22,8 & 22,7 & 23,4 & 23,7 & 22,2 & 22,9 & 23,7 & 22,3 & 22,1 \\
\hline \multirow{4}{*}{$\begin{array}{c}\text { Nitrogênio } \\
\text { Total } \\
\left(\mathrm{mg} \cdot \mathrm{L}^{-1}\right)\end{array}$} & $1^{a}$ & 0,5 & 0,7 & 6,9 & - & 1,9 & - & 0,7 & 4,1 & - & 1,8 & - & 1,5 & 0,7 & 2,3 & 2,4 \\
\hline & $2^{\mathbf{a}}$ & 0,8 & 0,5 & 5,8 & - & 1,1 & - & 0,7 & 3,0 & - & 1,3 & - & 5,0 & 2,0 & 3,3 & 5,6 \\
\hline & $3^{a}$ & 0,7 & 0,6 & 2,8 & 2,4 & 1,2 & 1,2 & 0,8 & 5,8 & 30,0 & 3,2 & 30,0 & 2,1 & 1,8 & 3,4 & 4,4 \\
\hline & $4^{a}$ & 3,0 & 0,6 & 3,6 & - & 1,9 & - & 0,6 & 3,8 & 11,4 & 1,4 & 5,0 & 1,0 & 4,2 & 2,3 & 2,1 \\
\hline \multirow{4}{*}{$\begin{array}{c}\text { Resíduo Total } \\
\left.\text { (mg. } \mathrm{L}^{-1}\right)\end{array}$} & $1^{\mathbf{a}}$ & 74,0 & 91,0 & $1.022,0$ & - & 508,0 & - & 478,0 & $3.703,0$ & - & 636,0 & - & $1.296,0$ & 467,0 & 486,5 & 507,0 \\
\hline & $2^{\mathbf{a}}$ & 58,0 & 99,0 & $1.797,0$ & - & 590,0 & - & 570,5 & $2.094,0$ & - & 811,0 & - & $4.841,0$ & 513,0 & 637,5 & 507,0 \\
\hline & $3^{\mathbf{a}}$ & 113,0 & 112,0 & $1.136,0$ & 383,0 & 484,0 & 394,0 & 774,0 & $3.074,0$ & $1.730,0$ & $1.002,0$ & 117,0 & 353,0 & 617,0 & 727,5 & 730,0 \\
\hline & $4^{a}$ & 799,5 & 723,0 & 810,0 & - & 808,0 & - & 754,0 & $2.004,0$ & $1.125,0$ & 984,0 & 77,9 & 734,0 & 838,0 & 996,5 & 741,0 \\
\hline
\end{tabular}

Fonte: dados secundários disponibilizados pelo Ministério da Integração Nacional Brasileiro. 
Embora os valores de temperatura mínima e máxima obtidos neste estudo, tenham sido registrados em áreas com presença (P3 - Paraíba) e ausência (P13 Pajeú) de matas ciliares, de modo geral observou que os dados registrados expressam valores semelhantes com outros corpos d'água do semiárido (MELO JUNIOR, COSTA e CABRAL NETO, 2003; CARVALHO et al., 2008; LIMA e GARCIA, 2008; BARRETO, ROCHA e OLIVEIRA, 2009; GARCIA et al., 2012).

Quanto ao nitrogênio total, as concentrações oscilaram entre $0,5 \mathrm{mg} \cdot \mathrm{L}^{-1} \mathrm{~N}$ na bacia do rio São Francisco (reservatório Itaparica - P1 e P2) a $30 \mathrm{mg} \cdot \mathrm{L}^{-1} \mathrm{~N}$ na bacia do rio Paraíba (P9 - Bodocongó) e na bacia do rio Pajeú (P11-Riacho do Navio, afluente do Açude Barra do Juá). Enquanto os valores de resíduo total foram entre 58 mg.L-1 (P1 - São Francisco) e 4841 mg.L-1 (P12 - Açude Barra do Juá - Eixo da Barragem - Pajeú). Os níveis de nitrogênio total e resíduo total encontrados nesta pesquisa são superiores ao registrados respectivamente por Mascarenhas et al. (2013) ao avaliarem também as estações de amostragens do eixo leste do PISF, e por Carvalho et al. (2008) no açude Bodocongó.

Em relação aos demais parâmetros avaliados $(\mathrm{pH}$, turbidez, OD, coliformes termotolerantes, DBO, fósforo total e clorofila-a) e que possuem limites preconizados pela legislação, observou que em cerca de $40 \%$ dos resultados as concentrações foram excedentes ao limite estabelecido pela Resolução CONAMA ํㅡ 357/2005 para águas classe II (Tabela 05). Nesse sentido é importante destacar que a não conformidade com a resolução pode restringir o uso da água para as atividades previstas nesta classe (PINHEIRO et al., 2014). Como por exemplo, sua utilização ao abastecimento humano (após tratamento convencional), a proteção de comunidades aquáticas, a recreação de contato primário, a irrigação de hortaliças e plantas frutíferas e a atividade de pesca.

Por motivo de organização, a relação do uso e ocupação do solo com as concentrações excedentes destas variáveis foi apresentada junto com a discussão dos índices aplicados nesta pesquisa, conforme a participação de influência de cada parâmetro para os valores encontrados nas estações amostrais analisadas. Os resultados para os índices avaliados encontram-se na Tabela 06. 
Tabela 05. Valores de pH, turbidez (UNT), OD (mg.t-1), coliformes termotolerantes (NMP.100 $\mathrm{mL}^{-1}$ ), DBO (mg. $\mathrm{L}^{-1}$ ), fósforo total $\left(\mathrm{mg} . \mathrm{L}^{-1}\right)$ e clorofila-a $\left(\mu \mathrm{g} . \mathrm{L}^{-1}\right)$ registrados nas estações amostrais das bacias dos rios São Francisco, Paraíba, Pajeú e Moxotó no período de 2013 a 2014. Dados ausentes(-). Campanhas( $1^{\mathrm{a}}, 2^{\mathrm{a}}, 3^{\mathrm{a}}$ e $\left.4^{\mathrm{a}}\right)$. Valores em negrito acima do permitido pela Resolução CONAMA 357/05 para águas classe II.

\begin{tabular}{|c|c|c|c|c|c|c|c|c|c|c|c|c|c|c|c|c|}
\hline \multirow[b]{2}{*}{ PARÂMETRO } & \multicolumn{3}{|c|}{$\begin{array}{c}\text { SÃO } \\
\text { FRANCISCO }\end{array}$} & \multicolumn{8}{|c|}{ PARAÍBA } & \multicolumn{3}{|c|}{ PAJEÚ } & \multicolumn{2}{|c|}{ MOXOTÓ } \\
\hline & & $\mathrm{P} 1$ & $\mathrm{P} 2$ & P3 & $\mathrm{P} 4$ & P5 & P6 & $\mathrm{P} 7$ & P8 & P9 & P10 & P11 & P12 & $\mathrm{P} 13$ & $\mathrm{P} 14$ & P15 \\
\hline \multirow{4}{*}{$\mathrm{pH}$} & $1^{\mathrm{a}}$ & 7,8 & 7,6 & 8,3 & - & 8,3 & - & 7,9 & 8,7 & - & 7,5 & - & 7,9 & 7,6 & 7,9 & 7,4 \\
\hline & $2^{\mathrm{a}}$ & 7,1 & 6,2 & 7,9 & - & 7,8 & - & 6,5 & 7,3 & - & 6,1 & - & 9,4 & 7,6 & 8,1 & 7,8 \\
\hline & $3^{\mathrm{a}}$ & 8,2 & 8,3 & 8,0 & 7,3 & 8,2 & 8,1 & 8,2 & 8,7 & 8,9 & 8,3 & 7,6 & 7,5 & 8,8 & 8,4 & 7,2 \\
\hline & $4^{-a}$ & 8,4 & 8,9 & 5,0 & - & 8,9 & - & 8,3 & 8,6 & 8,2 & 8,5 & 8,4 & 8,9 & 7,8 & 7,8 & 7,7 \\
\hline \multirow{4}{*}{ turbidez (UNT) } & $1^{\mathrm{a}}$ & 9,1 & 8,0 & 89,7 & - & 3,1 & - & 0,4 & 67,5 & - & 4,0 & - & 28,5 & 2,8 & 22,4 & 5,0 \\
\hline & $2^{\mathrm{a}}$ & 7,8 & 6,0 & 53,5 & - & 10,1 & - & 3,8 & 72,0 & - & 2,5 & - & 98,9 & 1,4 & 26,3 & 4,9 \\
\hline & $3^{\mathrm{a}}$ & 3,6 & 5,2 & 10,1 & 200,0 & 14,3 & 32,0 & 1,4 & 107,0 & 28,6 & 9,9 & 88,9 & 50,4 & 3,4 & 46,4 & 10,9 \\
\hline & $4^{\underline{a}}$ & 4,0 & 3,9 & 21,3 & - & 10,1 & - & 0,9 & 25,5 & 6,5 & 8,9 & 5,8 & 27,1 & 4,9 & 17,4 & 3,9 \\
\hline \multirow{4}{*}{$\mathrm{OD}\left(\mathrm{mg} \cdot \mathrm{L}^{-1}\right)$} & 1 & 7,8 & 6,9 & 6,3 & - & 8,0 & - & 5,8 & 6,8 & - & 7,6 & - & 6,1 & 8,1 & 6,7 & 7,2 \\
\hline & $2^{\mathrm{a}}$ & 8,2 & 9,3 & 10,4 & - & 7,7 & - & 9,3 & 11,9 & - & 8,2 & - & 10,4 & 8,5 & 7,1 & 9,3 \\
\hline & $3^{\mathrm{a}}$ & 9,3 & 7,6 & 8,4 & 2,7 & 8,2 & 7,1 & 6,5 & 8,9 & 8,5 & 7,1 & 8,3 & 7,9 & 13,5 & 4,0 & 3,4 \\
\hline & $4^{\underline{a}}$ & 10,7 & 9,7 & 6,2 & - & 9,8 & - & 10,4 & 9,9 & 8,0 & 10,1 & 9,6 & 9,6 & 6,3 & 4,7 & 9,3 \\
\hline \multirow{4}{*}{$\begin{array}{c}\text { Coliformes } \\
\text { termotolerantes } \\
(\mathrm{NMP} / 100 \mathrm{~mL})\end{array}$} & $1^{\mathrm{a}}$ & 4,0 & 13,5 & 43,0 & - & 43,0 & - & 23,5 & $1.100,0$ & - & $1.100,0$ & - & 9,0 & 11,0 & 0,0 & 21,0 \\
\hline & $2^{\underline{a}}$ & 7,5 & 2,0 & - & - & - & - & - & 94,0 & - & 23,0 & - & 13,0 & 33,0 & 3,3 & 79,0 \\
\hline & $3^{\mathrm{a}}$ & 105,0 & 94,5 & 13,0 & $1.601,0$ & 32,0 & 33,0 & 17,0 & 79,0 & 49,0 & 7,8 & $1.600,0$ & 79,0 & 70,0 & 41,0 & 920,0 \\
\hline & $4^{\mathrm{a}}$ & 13,0 & - & 71,5 & - & 79,0 & - & 240,0 & 1,8 & 540,0 & 14,0 & 34,0 & 17,0 & 9,2 & 2,0 & 22,0 \\
\hline \multirow{4}{*}{$\mathrm{DBO}\left(\mathrm{mg} \cdot \mathrm{L}^{-1}\right)$} & $1^{\mathrm{a}}$ & 26,4 & 18,4 & 64,4 & - & 33,4 & - & 22,0 & 100,0 & - & 20,0 & - & 18,0 & 24,0 & 64,4 & 50,4 \\
\hline & $2^{\mathrm{a}}$ & 11,5 & 10,1 & 71,9 & - & 32,5 & - & - & 107,3 & - & 18,4 & - & 121,7 & 31,1 & 46,8 & 45,2 \\
\hline & $3^{\mathrm{a}}$ & 17,2 & 13,5 & 89,5 & 37,3 & 30,2 & 21,4 & 8,2 & 121,8 & 59,7 & 34,5 & 68,9 & 54,3 & 46,3 & 36,5 & 40,1 \\
\hline & $4^{\mathrm{a}}$ & 4,2 & 5,2 & 23,5 & - & 8,6 & - & 14,7 & 124,8 & 52,4 & 19,9 & 35,2 & 38,5 & 18,3 & 192,8 & 62,1 \\
\hline \multirow{4}{*}{$\begin{array}{l}\text { fósforo total } \\
\left(\mathrm{mg}^{-1}\right)\end{array}$} & 1 & 1,6 & 1,2 & 1,8 & - & 0,2 & - & 0,4 & 3,8 & - & 0,7 & - & 0,8 & 3,8 & 1,0 & 1,0 \\
\hline & $2^{\mathrm{a}}$ & 0,3 & 0,9 & 0,4 & - & 0,2 & - & 0,3 & 1,0 & - & 0,3 & - & 1,4 & 0,9 & 0,3 & 0,8 \\
\hline & $3^{\underline{a}}$ & 0,9 & 0,9 & 1,2 & 1,2 & 0,8 & 0,9 & 0,2 & 1,1 & 2,5 & 0,4 & 7,1 & 1,2 & 0,7 & 0,8 & 1,8 \\
\hline & $4^{\mathrm{a}}$ & 0,1 & 0,2 & 0,1 & - & 0,1 & - & 0,2 & 0,9 & 3,8 & 0,2 & 1,4 & 0,1 & 0,3 & 0,2 & 0,3 \\
\hline \multirow{4}{*}{ clorofila-a $\left(\mu \mathrm{g} \cdot \mathrm{L}^{-1}\right)$} & $1^{\text {a }}$ & 0,1 & 0,1 & 6,0 & - & - & - & - & 1,6 & - & - & - & - & - & 0,2 & 0,1 \\
\hline & $2^{\underline{a}}$ & 6,3 & - & 209,8 & - & - & - & - & 154,9 & - & 8,0 & - & 309,0 & - & 49,7 & 20,5 \\
\hline & $3^{\mathbf{a}}$ & - & - & 7,0 & 93,2 & 10,4 & 28,8 & 12,0 & 248,3 & 290,3 & 15,2 & 52,3 & 44,2 & - & 128,3 & 8,1 \\
\hline & $4^{\mathrm{a}}$ & - & - & 62,4 & - & 26,5 & - & - & 245,9 & 7,9 & 17,4 & 18,4 & - & 25,2 & 22,1 & - \\
\hline
\end{tabular}

Fonte: dados secundários disponibilizados pelo Ministério da Integração Nacional Brasileiro. 
Tabela 06. IQA, IETm, IB e ICF registrados nas estações amostrais das bacias do rio São Francisco, Paraíba, Pajeú e Moxotó, no período de 2013 a 2014. Ótima (OT), Boa (BO), Regular (RE), Ruim (RU), Péssima (PE), Ultraoligotrófico (U), Oligotrófico (O),

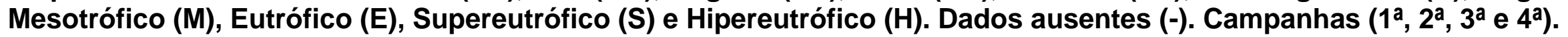

\begin{tabular}{|c|c|c|c|c|c|c|c|c|c|c|c|c|c|c|c|}
\hline & \multicolumn{2}{|c|}{ SÃO FRANCISCO } & \multicolumn{8}{|c|}{ PARAÍBA } & \multicolumn{3}{|c|}{ PAJEÚ } & \multicolumn{2}{|c|}{ мохото́ } \\
\hline & P1 & P2 & P3 & P4 & P5 & P6 & P7 & P8 & P9 & P10 & P11 & P12 & P13 & P14 & P15 \\
\hline & \multicolumn{15}{|c|}{ IQA } \\
\hline $1^{\mathrm{a}}$ & (49) RE & (50) RE & (30) RU & - & (45) RE & - & (48) RE & (25) RU & - & (43) RE & - & (46) RE & (43) RE & (40) RE & (39) RE \\
\hline $2^{\mathrm{a}}$ & (79) OT & (73) BO & (47) RE & - & (55) BO & - & (80) OT & (34) RU & - & (59) BO & - & (33) RU & (45) RE & (49) RE & (43) RE \\
\hline $3^{\mathbf{a}}$ & (56) BO & (66) BO & (44) RE & (24) RU & (45) RE & (52) BO & (73) BO & (31) RU & (35) RU & (49) RE & (32) RU & (41) RE & (38) RE & (36) RU & (32) RU \\
\hline \multirow[t]{2}{*}{$4^{\mathbf{a}}$} & (70) BO & (76) BO & (46) RE & - & (66) BO & - & (65) BO & (45) RE & (35) RU & (60) BO & (44) RE & (48) RE & (59) BO & (48) RE & (50) RE \\
\hline & \multicolumn{15}{|c|}{ IETm } \\
\hline $1^{\mathrm{a}}$ & $(41,0) \cup$ & $(38,6) \cup$ & $(50,7) \bigcirc$ & - & $(30,8) \cup$ & - & $(36,1) \cup$ & $(45,9) \cup$ & - & $(31,9) \cup$ & - & $(41,2) \cup$ & $(40,9) \cup$ & $(40,6) \cup$ & $(32,0) \cup$ \\
\hline $2^{\mathbf{a}}$ & $(45,7) \cup$ & $(41,9) \cup$ & $(55,1) \mathrm{M}$ & - & $(33,4) \cup$ & - & $(34,6) \cup$ & $(62,3) \mathrm{E}$ & - & $(46,0) \cup$ & - & $(59,5) \mathrm{E}$ & $(33,5) \cup$ & $(50,8) \bigcirc$ & $(54,60) \mathrm{M}$ \\
\hline $3^{\mathbf{a}}$ & $(41,7) \cup$ & $(41,9) \cup$ & $(49,8) \bigcirc$ & $(62,1) \mathrm{E}$ & $(49,6) \bigcirc$ & $(54,7) \mathrm{M}$ & $(45,4) \cup$ & $(64,6) \mathrm{S}$ & $(67,4) \mathrm{H}$ & $(49,7) \bigcirc$ & $(62,7) \mathrm{E}$ & $(54,3) \mathrm{M}$ & $(31,9) \cup$ & $(55,7) \mathrm{M}$ & $(52,6) \mathrm{M}$ \\
\hline \multirow[t]{2}{*}{$4^{a}$} & $(30,6) \cup$ & $(30,8) \cup$ & $(47,0) \cup$ & - & $(45,6) \cup$ & - & $(33,1) \cup$ & $(64,0) \mathrm{S}$ & $(52,9) \mathrm{M}$ & $(48,2) \bigcirc$ & $(54,0) \mathrm{M}$ & $(25,3) \cup$ & $(52,6) \mathrm{M}$ & $(46,4) \cup$ & $(26,7) \cup$ \\
\hline & \multicolumn{15}{|c|}{ IB } \\
\hline $1^{\mathrm{a}}$ & OT & OT & OT & - & OT & OT & OT & $\mathrm{RE}$ & - & $\mathrm{RE}$ & - & OT & OT & OT & OT \\
\hline $2^{\mathbf{a}}$ & OT & OT & OT & - & OT & OT & OT & OT & - & OT & - & OT & OT & OT & OT \\
\hline $3^{\mathbf{a}}$ & OT & OT & OT & PE & OT & OT & OT & OT & OT & OT & $\mathrm{RU}$ & OT & OT & OT & BO \\
\hline \multirow[t]{2}{*}{$4^{\mathrm{a}}$} & OT & OT & OT & - & OT & OT & OT & OT & BO & OT & OT & OT & OT & OT & OT \\
\hline & \multicolumn{15}{|c|}{ ICF } \\
\hline $1^{\mathrm{a}}$ & $\mathrm{RE}$ & $\mathrm{RE}$ & - & - & - & - & BO & $\mathrm{RE}$ & - & $\mathrm{RE}$ & - & $\mathrm{RE}$ & BO & $\mathrm{RE}$ & - \\
\hline $2^{\mathbf{a}}$ & BO & BO & - & - & $\mathrm{RE}$ & - & BO & - & - & - & - & $\mathrm{RU}$ & $\mathrm{RE}$ & - & - \\
\hline $3^{\mathbf{a}}$ & $\mathrm{RE}$ & $\mathrm{RE}$ & $\mathrm{RE}$ & $\mathrm{RE}$ & BO & BO & - & $\mathrm{RE}$ & $\mathrm{RU}$ & $\mathrm{RE}$ & $\mathrm{RE}$ & - & BO & $\mathrm{RU}$ & $\mathrm{RU}$ \\
\hline $4^{\mathrm{a}}$ & BO & BO & $\mathrm{RE}$ & - & - & - & BO & $\mathrm{RE}$ & $\mathrm{RE}$ & $\mathrm{RE}$ & - & BO & $\mathrm{RE}$ & $\mathrm{RE}$ & $\mathrm{RE}$ \\
\hline
\end{tabular}

Fonte: calculado pelos autores com resultados da pesquisa. 
De acordo com o IQA observa-se que no geral a qualidade da água nos pontos amostrais encontra-se classificada como regular (49\%) assim como demonstrado em pesquisas desenvolvidas na sub-bacia do córrego André-MT (BARROS, SOUZA e SOUZA, 2011), no açude Soledade - PB (CARVALHO et al., 2011) e na Lagoa do Apodi - RN (PINTO FILHO, SANTOS e SOUZA, 2012), onde verificou o predomínio de qualidade da água nesse nível, representando respectivamente, $60 \%, 45,86 \%$ e $54 \%$ dos resultados.

Na bacia dos rios Paraíba (P3, P4, P8 e P9), Pajeú (P11 e P12) e Moxotó (P14 e P15) foram registrados os menores valores de IQA, e consequentemente onde qualidade da água foi classificada em nível mais baixo (classe ruim) durante 0 estudo. Em trabalhos realizados no Nordeste (MELO JÚNIOR, COSTA e CABRAL NETO, 2003; ARAÚJO, SANTOS e ARAÚJO, 2007; ROCHA et al., 2010; SILVA e SOUZA, 2013) e em outras regiões brasileiras (BARROS, SOUZA e SOUZA, 2011; NUNES, SILVA e MATOS, 2011; FRANCO e HERNANDEZ, 2012) foi constatado, como neste estudo, baixos valores de IQA associados a níveis elevados de fósforo total, turbidez, coliformes termotolerantes, DBO, resíduo total e baixas concentrações de oxigênio dissolvido provocado pelo uso e ocupação do solo.

$\mathrm{Na}$ literatura o processo erosivo do solo, desmatamento das matas ciliares e despejo de esgoto sem tratamento foram apontados como responsáveis pelos valores elevados de turbidez e DBO (VASCO et al., 2011; BEZERRA et al., 2013 e FREIRE et al., 2013), bem como para ocorrência de baixas concentrações de oxigênio dissolvido (SILVA, SOUSA e KAYANO, 2007; DAMASCENO et al., 2008; FONTENELE et al., 2011; VASCO et al., 2011; SILVA e DANTAS NETO, 2014 e SOUZA et al., 2014) em cursos d'água.

No presente estudo associada as atividades descritas anteriormente, outras fontes antrópicas podem ter contribuído para elevação dos níveis de turbidez e DBO, e as baixas concentrações de oxigênio dissolvido. Como por exemplo, a presença de pastos, acesso de animais no espelho d'água, currais, áreas destinadas ao cultivo agrícola, faixas de assoreamento e extração de areia registrado nas estações amostrais.

Os resultados do IET médio (IETm) apresentaram o predomínio das classes Ultraoligotrófica (56\%), Oligotrófica (12\%) e Mesotrófica (18\%), que caracteriza baixos teores de nutrientes ou em níveis aceitáveis (BARBOSA et al., 2006; CASTRO, FERREIRA e MATTOS, 2009; CETESB, 2012).

Estações amostrais com níveis elevados de fósforo total e teor de clorofila-a 
foram classificadas como Eutróficas (P4 e P8 - Paraíba; P11 e P12 - Pajeú), Supereutróficas (P8) e Hipereutróficas (P9 - Paraíba), corroborando com os resultados encontrados por Barreto et al. (2014) para o rio Catolé Grande - BA e por Batista et al. (2014) ao avaliarem a qualidade da água do açude Orós - CE, onde também verificaram água nestes níveis tróficos.

Em se tratando de qualidade da água dos rios que drenam o semiárido o principal problema é o lançamento de esgotos domésticos. Nas cidades, a ineficiência na coleta, no tratamento e na disposição final dos resíduos sólidos vem causando a poluição dos corpos d'água superficiais e subterrâneos, comprometendo o aproveitamento dos mananciais e causando problemas de saúde (ZANELLA, 2014).

As descargas de esgotos in natura e as atividades agropecuárias são as principais origens do aporte de fósforo e nitrogênio nos mananciais (PALÁCIO et al., 2009; ALEXANDRE et al., 2010; OLIVEIRA, CAMPOS e MEDEIROS, 2010; CARVALHO et al., 2008; LIMA e GARCIA, 2008; SILVA e SOUZA, 2013).

Além disso, trabalhos realizados na bacia hidrográfica do rio Curu - $\mathrm{CE}$ (GORAYEB et al., 2007), em reservatórios da Paraíba (LUCENA, MENEZES e SASSI, 2008), no rio Poxim - SE (VASCOS et al., 2011), no rio Apodi-Mossoró - RN (BEZERRA et al., 2013), no rio Catolé - BA (SANTOS et al., 2013) e no rio Almada BA (SOUZA et al., 2014) registraram valor máximo de fósforo total em estações amostrais com presença das referidas atividades. Vasco e colaboradores (2011) salientam que a disponibilidade de nutrientes em excesso provocada pelo aporte de atividades antrópicas no entorno das estações amostrais, propiciam maior teor de clorofila-a.

Neste estudo foram identificadas atividades agropecuárias, lançamento de esgoto, degradação da mata ciliar, construções de imóveis e disposição inadequada de resíduos sólidos no seu entorno nas estações amostrais com alta produtividade (Eutrófico, Supereutrófico e Hipereutrófico). Esse fato pode ter contribuído para o registro das concentrações máximas e em desacordo com a legislação de fósforo total e clorofila-a, justificando desta forma os altos níveis de estado trófico encontrados.

Nas visitas in loco também observou proliferação de macrófitas aquáticas: Ninféia (Nymphaea sp.) e Lentilha d'água (Lemna sp.); e algas (Clorophyta). Possivelmente a presença desses autótrofos é fruto do incremento de nutrientes na água. Araújo, Santos e Araújo (2007) e Batista et al. (2014) também registraram 
situação semelhante, onde verificaram proliferação de vegetação aquática em águas com níveis elevados de nutrientes.

Quanto à análise para IB a qualidade da água nas estações amostrais foi classificada como própria (ótima e boa) e imprópria (regular, ruim, péssima). Resultados diferentes foram encontrados para o açude Soledade (CARVALHO, MORAES NETO e LIMA, 2010) e o açude de Bodocongó (CARVALHO et al., 2009), ambos localizados no estado da Paraíba, e onde suas águas foram classificadas como impróprias em todas as amostras.

Águas classificadas como impróprias (regular, ruim, péssima) foram registradas em estações amostrais apenas da bacia dos rios Paraíba (P4, P8 e PA 10) e Pajéu (P11). Os níveis elevados de coliformes termotolerantes ao admitido pela Resolução CONAMA 357/5 (limite de 1000 NMP.100mL-1) nas referidas estações amostrais pode ser resultado da presença de atividades antrópicas (dessedentação de animais, presença de currais, descarte de resíduos sólidos, despejo de esgoto sem tratamento, recreação contato primário e conjuntos habitacionais nas proximidades), como também foi constatado em outras pesquisas desenvolvidas no Nordeste: no Rio Grande do Norte (ARAÚJO, SANTOS e ARAÚJO, 2007 e SILVA e SOUZA, 2013), no Ceará (GORAYEB et al., 2007 e DAMASCENO et al., 2008), na Bahia (CUNHA et al., 2010 e OLIVEIRA, CAMPOS e MEDEIROS, 2010) e na Paraíba (PEREIRA JUNIOR, ALVES e GAMA, 2011).

Com base no índice de comunidade fitoplanctônica (ICF), com exceção para P6 e P7, os reservatórios e rios estudados foram classificados como Regular pelo menos uma vez durante o período de estudo. Nesses pontos, assim como os classificados como ruim, ocorreram os valores mais elevados de densidade média da comunidade fitoplanctônica, e as Cyanophyceae (cianobactérias) como grupo dominante, corroborando com os resultados encontrados para o reservatório Billings-SP (CETESB, 2014).

Analisando também as estações do eixo leste do PISF, Mascarenhas et al. (2013) constataram predominância das Cyanophyta sobre os demais táxons e contribuindo com as maiores densidades, durante todo o período de estudo. Os referidos autores, ainda enfatizaram a importância do monitoramento contínuo, visto que esses organismos são potencialmente produtores de toxinas.

Em estudos realizados ao longo da bacia do Rio Piranhas-Açu, Cardoso et. al. (2017) resulta que a comunidade fitoplanctônica esteve distribuída em nove classes; a divisão Chlorophyta foi a mais representativa em riqueza de espécies, seguida das 
cianobactérias, essa alta densidade das cianobactérias pode estar relacionada ao alto tempo de residência da água em reservatórios e às características climáticas locais de altas temperaturas e radiação solar.

A ocorrência desses microrganismos nas estações amostrais pode ser justificada em função dos elevados níveis de nutriente (fósforo total superior ao limite preconizado na legislação) encontrado neste estudo, que favorece o desenvolvimento das algas.

\section{Análise estatística}

A análise de componentes principais (ACP) demonstrou a formação de nove componentes principais. De acordo com critério seguido por Gardiman Júnior (2015) e Guedes et al. (2012), o número ideal de componentes selecionadas para explicar o comportamento das variáveis de qualidade de água deve ser aquele represente entre 70 - 90\% da variância total.

As cinco primeiras componentes foram responsáveis juntas por $92,93 \%$ da variação total dos dados, e, portanto, selecionadas. Na componente 1 o nitrogênio total foi o parâmetro mais significativo; para a componente 2 identificou a clorofila-a; já a componente 3 esteve expressa pela DBO e resíduo total, enquanto a componente 4 e 5 foi explicada, respectivamente pelo resíduo total e fósforo total (Tabela 07). Estas variáveis apresentaram pesos ("loadings") elevados comparado às demais inseridas em cada componente, constituindo desta forma as variáveis mais significativas para formação das componentes principais e na determinação da qualidade da água (ANDRADE et al., 2007b; GIRÃO et al., 2007, GUEDES et al., 2012).

Tabela 07. Matriz do peso fatorial das variáveis nas cinco componentes selecionadas nas estações amostrais das bacias hidrográficas dos rios São Francisco, Paraíba, Pajeú e Moxotó no período de 2013 a 2014.

\begin{tabular}{cccccc}
\hline Variável & CP1 & CP2 & CP3 & CP4 & CP5 \\
\hline T & 0,03 & $-0,07$ & $-0,01$ & 0,23 & $-0,19$ \\
pH & 0,05 & $-0,24$ & 0,13 & 0,04 & $-0,07$ \\
Turb. & $-0,36$ & 0,06 & $-0,17$ & 0,45 & 0,24 \\
OD & 0,21 & $-0,24$ & 0,07 & 0,46 & $-0,35$ \\
\hline
\end{tabular}




\begin{tabular}{cccccc}
\hline CT & 0,31 & 0,40 & $-0,43$ & 0,38 & 0,15 \\
DBO & 0,20 & 0,09 & $\mathbf{0 , 6 5}$ & $-0,10$ & 0,44 \\
NT & $\mathbf{0 , 6 6}$ & 0,17 & 0,04 & $-0,12$ & $-0,39$ \\
RsT & $-0,09$ & 0,34 & $\mathbf{0 , 5 5}$ & $\mathbf{0 , 5 1}$ & $-0,10$ \\
PT & 0,45 & $-0,07$ & $-0,13$ & 0,11 & $\mathbf{0 , 5 9}$ \\
CL & $-0,13$ & $\mathbf{0 , 7 3}$ & $-0,04$ & $-0,24$ & $-0,13$ \\
\hline \% variância explicada & 33,82 & 25,99 & 18,23 & 8,46 & 6,44 \\
\% variância & 33,82 & 59,81 & 78,04 & 86,50 & 92,93 \\
acumulada & & & & & \\
\hline
\end{tabular}

Fonte: calculado pelos autores com resultados da pesquisa.

Deste modo, verifica-se que a(s) variável(is) mais significativas nas componentes 1,2,3,4 e 5 estão relacionadas a produção social do espaço, isto é, as práticas socioespaciais e atividades produtivas existentes no entorno de cada estação amostral.

Como por exemplo, o desenvolvimento de atividades agropecuárias; lançamento de esgoto sem tratamento, disposição inadequada de resíduos sólidos nas margens dos cursos d'água, supressão da cobertura ciliar, bem como concernentes ao processo de eutrofização, conforme registros encontrados na literatura para bacia do Baixo Acaraú (ANDRADE et al., 2007a), Alto Acaraú (ANDRADE et al., 2007b) e no Rio Jaibaras (GIRÃO et al., 2007), todos situados no estado do Ceará; para a bacia do Alto curso do rio das Velhas (NONATO et al., 2007) e o médio rio Pomba (GUEDES et al., 2012), ambos localizados em Minas Gerais; e também para a bacia do rio Jucu, no estado do Espírito Santo (GARDIMAN JUNIOR, 2015).

Assim esses resultados, indicam que a diversidade do uso e ocupação do solo presentes nas margens das estações amostrais analisadas contribui para 0 aumento na carga de nutrientes e sedimentos, participando neste caso como fator determinante para qualidade da água e evidenciando a ação antrópica negativa para as bacias em estudo, como já reportado na discussão dos índices (IQA, IET, IB e ICF) e parâmetros avaliados. 


\section{Considerações Finais}

O estudo permite apontar que a diversidade de uso e ocupação do solo no entorno das estações amostrais analisados no eixo leste do PISF contribuem para a degradação da qualidade da água. Além de parâmetros $(\mathrm{pH}$, turbidez, OD, coliformes termotolerantes, DBO, fósforo total e clorofila-a) encontrarem em não conformidade com os limites estabelecidos pela resolução CONAMA № 357/2005 para as águas classe II.

A aplicação dos índices evidencia água com baixos níveis de qualidade (IQARegular e Ruim; IB- Imprópria; ICF- Regular e Ruim) e altos níveis de eutrofização (IET- Eutrófico, Supereutrófico e Hipereutrófico) apresentando resultados satisfatórios na caracterização da qualidade da água para estações analisadas.

A análise de componentes principais demonstrou indicadores hídricos associados a teores excessivos de carga orgânica e de nutrientes nos corpos d'água avaliados, comprovando a influência antrópica relatada no estudo.

Das quatro bacias em estudo, a do rio Paraíba foi a única que apresentou todos os parâmetros analisados em desacordo com a legislação, em pelo menos uma das estações amostrais durante as quatro campanhas de coleta. O rio Paraíba Montante do Remanso do Açude Camalaú (P4) foi onde ocorreu maior registro de parâmetros em desacordo (seis dos setes analisados), com exceção apenas do pH.

Espera-se, que os resultados apresentados neste estudo forneçam subsídio para futuras pesquisas e investimentos na gestão integrada dos ecossistemas hídricos analisados, reforçando o desenvolvimento de trabalhos de monitoramentos.

\section{REFERÊNCIAS}

ALEXANDRE, D. M. B. et al. The water quality investigation using GIS and multivariable analysis in a semiarid region reservoir. Revista Ciência Agronômica, Fortaleza, v.41, n.4, p.554-561, 2010.

ALMEIDA, M. B.; SCHWARZBOLD, A. Avaliação sazonal da qualidade das águas do Arroi da Cria Montenegro, RS com aplicação de um índice de qualidade de água (IQA). Revista Brasileira de Recursos Hídricos, Porto Alegre, v.8, n.1, p.81-97, 2003.

APHA - AMERICAN PUBLIC HEALTH ASSOCIATION. ATON, A. D., CLESCERI, L. C.; GREEBERG, A. E. (2000) (eds.) Standard Methods for the Examination of Water and Wastewater. 21 ed. Washington, D. C.: APHA.

ARAÚJO, V. S.; SANTOS, J. P.; ARAÚJO, A. L. C. Monitoramento das águas do Rio Mossoró/RN, no perímetro de abril/2005 a julho/2006. Revista Holos, Rio Grande do Norte, v.1, n. 23, p.4 - 41, 2007. 
BARBOSA, J. E. L. et al. Diagnóstico do estado trófico e aspectos limnológicos de sistemas aquáticos da Bacia Hidrográfica do Rio Taperoá, Trópico semiárido Brasileiro. Revista de Biologia e Ciências da Terra. Suplemento Especial, Sergipe, n.1, p.81-89, 2006.

BARRETO, L. V.; ROCHA, F. A.; OLIVEIRA, M. S. C. Monitoramento da qualidade da água na microbacia Hidrográfica do rio catolé, em Itapetinga - BA. Centro Científico Conhecer Encliclopédia Biosfera, Goiânia, v.5, n.8, p.1-9, 2009.

BARROS, R. V. G.; SOUZA, H. M. de L.; SOUZA, C. A. Determinação do índice de qualidade da água (IQA) na sub-bacia do Córrego André em Mirassol D’Oeste, Mato Grosso. Engenharia Ambiental, Espírito Santo do Pinhal, v.8, n.3, p.138 -153, 2011.

BATISTA , A. A. et al. Sazonalidade e variação espacial do índice de estado trófico do açude Orós, Ceará, Brasil. Revista Agroambiente, Boa Vista, v.8, n.1, p. 39 - 48, 2014.

BEZERRA, J. M. et al. Análise dos indicadores de qualidade da água no trecho urbano do Rio Apodi-Mossoró em Mossoró-RN, Brasil. Ciências Agrárias, Londrina, v. 34, n. 6 , suplemento 1, p.3443 - 3454, 2013.

CABRAL, J. B. P. et al. Avaliação sazonal e monitoramento das águas do rio Doce - GO. Geoambiente - Revista Eletrônica do Curso de Geografia- UFG/REJ, Jataí, n.24, p.115133, 2015.

CARDOSO, A. S. et al. Análise da presença do fitoplâncton em bacia integrante do Projeto de Integração do Rio São Francisco, região semiárida, Nordeste brasileiro. Engenharia Sanitária Ambiental, Rio de Janeiro, v. 22, n. 2, p. 261-269, 2017.

CARVALHO, A. P. et al. Aspectos qualitativos da água do açude de Bodocongó em Campina Grande - PB. Engenharia Ambiental, Espírito Santo do Pinhal, v.5, n.2, p.94 109, 2008.

CARVALHO, A. P. et al. Determinação do índice de balneabilidade do açude de Bodocongó em Campina Grande, PB, Brasil, a partir de indicadores biológicos. Educação Ambiental em Ação, n. 28, 2009.

CARVALHO, A. P; MORAES NETO, J. M.; LIMA, V. L. A. Avaliação do índice de Balneabilidade a partir de indicadores biológicos do açude Soledade em Soledade, Paraíba, Brasil. Engenharia Ambiental, Espírito Santo do Pinhal, v. 7, n. 2, p. 263 - 273, 2010.

CARVALHO, A. P. et al. Determinação espacial e temporal do IQA do açude Soledade em Soledade - Paraíba. Engenharia Ambiental, Espírito Santo do Pinhal, v. 8, n. 2, p.138 -147, 2011.

CARVALHO, A. R.; MELO, J. A. B. Análise ambiental e repercussão do problema da água dos açudes da cidade de Pocinhos - PB. Caminhos de Geografia, Uberlândia, v.13, n. 44, p. $198-211,2012$.

CASTRO, M. G. G. M; FERREIRA, A. P; MATTOS, I. E. Avaliação da qualidade da água nos Assentamentos de Reforma Agrária Bernardo Marin II e Mundo Novo, município de Russas (Ceará, Brasil): um estudo de caso. Gaia Scentia, Paraíba, v.3, n.1 p.63-70, 2009.

COELHO, G. et al. Qualidade da água do Ribeirão Lavrinha na região alto rio Grande-MG, Brasil. Ciência Agrotecnologia, Lavras, v.33, n.4, p.1145 - 1152, 2009. 
COMPANHIA AMBIENTAL DO ESTADO DE SÃO PAULO - CETESB. Relatório de qualidade das águas interiores do Estado de São Paulo. 2012, 2014. São Paulo, SP: CETESB, 2014. 434 p.

CONSELHO NACIONAL DO MEIO AMBIENTE. Resolução CONAMA no 357, de 17 de março de 2005. Disponível em: <http://www.mma.gov.br/port/conama/ > Acessado em 23 de janeiro de 2015 .

CUNHA, A. R. et al. Análise microbiológica da água do rio Itanhém em Teixeira de FreitasBA. Revista Biociências, Taubaté, v. 16, n. 2, p. 86 - 93, 2010.

DAMASCENO, L. M. O. et al. Qualidade da água do rio Poty para consumo humano, na região de Teresina, PI. Revista Verde, Mossoró, v.3, n.3, p.116 -130, 2008.

DONADIO, N. M. M; GALBIATTI, J. A; PAULA, R. C. Qualidade da água de nascentes com diferentes usos do solo na bacia hidrográfica do Córrego Rico, São Paulo, Brasil.

Engenharia Agrícola, Jaboticabal, v. 25, n. 1, p.115 - 125, 2005.

FONTENELE, S. B. et al. Análise espaço-temporal da qualidade da água na parte alta da bacia do rio Salgado, Ceará. Revista Caatinga, Mossoró, v. 24, n. 3, p.102-109, 2011.

FRACALANZA, A. P. Água: De elemento natural a mercadoria. Sociedade e Natureza, Uberlândia, v. 17, n. 33, p. 21 - 36, 2005.

FRANCO, R. A. M.; HERNANDEZ, F. B. T. Qualidade da água para irrigação na microbacia do Coqueiro, Estado de São Paulo. Revista Brasileira de Engenharia Ambiental, Campina Grande, v.13, n. 6, p. 772 - 780, 2009.

FREIRE, F. G. C. et al. Indicadores de qualidade da água no rio Jaguaribe em São João do Jaguaribe - CE. Irriga, Botucatu, v.18, n. 4, p. 700 - 707, 2013.

GARCIA, H. L. et al. Nível trófico do reservatório de Jacarecica I - Sergipe - Brasil. Scientia Plena, Sergipe, v. 8, n. 7, 2012.

GARDIMAN JUNIOR, B. S. Caracterização do processo de poluição das águas superficiais da Bacia Hidrográfica do rio Jucu, estado do Espírito Santo, Brasil. Revista Agroambiente, Boa Vista, v. 9, n. 3, p. $235-242,2015$.

GIRÃO, E. G. et al. Seleção dos indicadores da qualidade de água no Rio Jaibaras pelo emprego da análise da componente principal. Revista Ciência Agronômica, Fortaleza, v. 38, n.1, p.17-24, 2007.

GUEDES, H. A. S. et al. Aplicação da análise estatística multivariada no estudo da qualidade da água do Rio Pomba, MG. Revista Brasileira de Engenharia Agrícola e Ambiental, Campina Grande, v.16, n.5, p. 558 - 563, 2012.

GORAYEB, A. et al. Aspectos ambientais e qualidade das águas superficiais na bacia hidrográfica do rio Curu - Ceará, Brasil. Holos Environment, Rio Claro, v. 7, n. 2, p.105 122, 2007.

HAMMER, Ø. et al. Manual de Referência PAST: Paleontological Statistics Software Package for Education and Data Analysis. Palaeontologia Electronica, v.4, n.1, p.1 - 9, 2001.

LIMA, W. S.; GARCIA C. A. B. Qualidade da água em Ribeirópolis - SE: O Açude do Cajueiro e a Barragem do João Ferreira. Scientia Plena, Sergipe, v.4, n.12, 2008. 
LUCENA, R. L.; MENEZES, M. F.; SASSI, R. Qualidade da água de reservatórios nas distintas zonas climáticas da Paraíba. Mercator- Revista de Geografia da UFC, Fortaleza, ano 7, n.14, p. 987-97, 2008.

MASCARENHAS, G.L. et al. Caracterização do fitoplâncton das bacias do rio São Francisco, Moxotó e Paraíba, inseridas no projeto de integração do rio São Francisco. Revista Brasileira de Geografia Física, Recife, v. 6, n. 5, p.1050 - 1068, 2013.

MELO JÚNIOR, G.; COSTA, C.E.F.S.; CABRAL NETO, I. Avaliação hidroquímica e da qualidade das águas de um trecho do rio Açu, Rio Grande do Norte. Revista de Geologia, Ceará, v.16, n. 2, p. $27-36,2003$.

MINISTÉRIO DA INTEGRAÇÃO NACIONAL. Disponível em <http://www.mi.gov.br/web/guest/o-que-e-o-projeto >Acessado em novembro de 2014.

NONATO, E. A. et al. Tratamento estatístico dos parâmetros da qualidade das águas da bacia do alto Curso do rio das Velhas. Química Nova, São Paulo, v. 30, n. 4, p.797-804, 2007.

OLIVEIRA, C. N.; CAMPOS, V. P.; MEDEIROS, Y. D. P. Avaliação e identificação de parâmetros importantes para a qualidade de corpos d'água no semiárido baiano. Estudo de caso: bacia hidrográfica do rio Salitre. Química Nova, São Paulo, v. 33, n. 5, p.1059-1066, 2010.

PALÁCIO, H. A. Q. et al. Similaridade da qualidade das águas superficiais da bacia do Curu, Ceará. Ciência Rural, Santa Maria, v. 39, n. 9, p. 2494 - 2500, 2009.

PEREIRA JÚNIOR, L. R.; ALVES, G. S.; GAMA, J. S. N. Diagnóstico da qualidade da água da Lagoa Bela Vista no Município de Cuité, Paraíba. Engenharia Ambiental, Espírito Santo do Pinhal, v. 8, n. 4, p. $46-61,2011$.

PINHEIRO, A. et al. Relação entre o uso do solo e a qualidade da água em bacia hidrográfica rural no bioma Mata Atlântica. Revista Brasileira de Recursos Hídricos, Porto Alegre, v. 19, n. 3, p. $127-139,2014$.

PINTO FILHO, J. L. O; SANTOS, E. G.; SOUZA, M. J. J. Proposta de índice de qualidade da água para a Lagoa do Apodi, RN, Brasil. Holos, Rio Grande do Norte, ano 8, v. 2, p. 69 76, 2012.

REIS, J. T.; PEREIRA FILHO, W. Influência do uso e ocupação da terra no ecossistema aquático da sub-bacia hidrográfica do Arroio Cadena, em Santa Maria, RS. Ciência e Natura, Santa Maria, v. 28, n.1, p. 75 - 90, 2006.

RIBEIRO, C. W. Conflitos distributivos e dívida ecológica. 2. ed., 1aㅡ reimpressão, São Paulo: Contexto, p. $9-12,2014$.

ROCHA, J. L. S. et al. Indicador integrado de qualidade ambiental aplicado à gestão da bacia hidrográfica do rio Jiquiriçá, BA. Revista Ambiente e Água - An Interdisciplinary Journal of Applied Science, Taubaté, v. 5, n. 1, p. 89 - 101, 2010.

SANTOS, Q. R. et al. Monitoramento da qualidade da água em uma seção transversal do rio Catolé, Itapetinga - BA. Centro Científico Conhecer - Enciclopédia Biosfera, Goiânia, v.9, n.16; p.1503-1519, 2013.

SILVA, D. F.; SOUSA, F. A. S.; KAYANO, M. T. Avaliação dos impactos da poluição nos recursos hídricos da bacia do rio Mundaú (AL e PE). Revista de Geografia, Recife, v. 24, n. 3, p. $210-223,2007$. 
SILVA, M. L. P.; DANTAS NETO, J. Avaliação preliminar da presença de metais traço, nas águas do riacho Mussuré e o córrego de Mumbaba - João Pessoa - PB. Revista Brasileira de Geografia Física, Recife, v. 7, n. 4, p. 668 - 677, 2014.

SILVA, M. B. R.; AZEVEDO, P. V.; ALVES, T. L. B. Análise da degradação ambiental no alto curso da bacia hidrográfica do rio Paraíba. Boletim Goiano de Geografia, Goiânia, v. 34, n. 1 , p. $35-53,2014$.

SILVA, A. G.; SOUZA, L. D. Efeitos antrópicos e sazonais na qualidade da água do rio do Carmo. Holos, Rio Grande do Norte, ano 29, v.5, p.122-136, 2013.

SOUZA, J. R. et al. A importância da qualidade da água e os seus múltiplos usos: Caso rio Almada, Sul da Bahia, Brasil. Revista Eletrônica do Prodema, Fortaleza, v.8, n.1, p. 26 45, 2014.

VASCO, A. N. et al. Avaliação espacial e temporal da qualidade da água na sub-bacia do rio Poxim, Sergipe, Brasil. Ambi-Água, Taubaté, v. 6, n.1, p.118-130, 2011.

ZANELLA, M. E. Considerações sobre o clima e os recursos hídricos do Semiárido Nordestino. Caderno Prudentino de Geografia, Presidente Prudente, n.36, Volume Especial, p. 126-142, 2014.

\section{NOTAS DE AUTOR}

\section{CONTRIBUIÇÃO DE AUTORIA}

Adriana Maria Cunha da Silva - Elaboração do manuscrito, revisão e aprovação da versão final do trabalho Maristela Casé - Concepção. Coleta de dados, Análise de dados, Elaboração do manuscrito, revisão e aprovação da versão final do trabalho. Participação ativa da discussão dos resultados.

Denise Vieira Lopes - Coleta de dados, Análise de dados. Elaboração do manuscrito. Participação ativa da discussão dos resultados.

\section{FINANCIAMENTO}

Denise Vieira Lopes foi aluna do curso de Mestrado em Ecologia humana e Gestão Socioambiental com bolsa da Fundação de Amparo à Pesquisa do Estado da Bahia (FAPESB). O Projeto de pesquisa desenvolvido no Departamento de Educação da Universidade do Estado da Bahia.

CONSENTIMENTO DE USO DE IMAGEM

Não se aplica.

APROVAÇÃO DE COMITÊ DE ÉTICA EM PESQUISA

Não se aplica.

CONFLITO DE INTERESSES

Não se aplica.

\section{LICENÇA DE USO}

Este artigo está licenciado sob a Licença Creative Commons CC-BY. Com essa licença você pode compartilhar, adaptar, criar para qualquer fim, desde que atribua a autoria da obra.

\section{HISTÓRICO}

Recebido em: 20-06-2018

Aprovado em: 15-01-2019 